\title{
Ciudad global y consumos culturales en Buenos Aires de fin de siglo XX: continuidades y rupturas del neoliberalismo.
}

\section{Global City and Cultural Consumption in Buenos Aires at the End of the XXth Century: Continuities and Ruptures of Neoliberalism.}

\begin{abstract}
Resumen
Como muchas ciudades latinoamericanas, Buenos Aires, durante la década de 1990, fue escenario de una serie de cambios vertiginosos que se asociaron, con mayor o menor énfasis, al imperativo de entrar en un escenario global. Zonas que décadas atrás eran orgullo de la metrópolis y donde el auge constructor del siglo XIX había afincado el poderío de un EstadoNación en crecimiento comenzaron a ser abandonadas en favor de barrios nuevos o reciclados que insinuaban una impronta estética o cultural. El neoliberalismo imprimió de esta manera sus signos en la ciudad: se produjo la formación, impulsada desde el Estado, de nuevos barrios (como Puerto Madero), el reciclaje de otros con una activa vida previa y en manos de emprendimientos privados (el barrio porteño de Palermo), el surgimiento de shoppings basados en la reconversión de estructuras industriales abandonadas, entre otros ejemplos. Después de la gran crisis argentina del año 2001, estos procesos fueron inscriptos en una oposición que sugería una ruptura entre la década neoliberal de los noventa y la década de los dos mil. Este artículo sostiene, por el contrario, que existe una continuidad cultural entre ambas décadas y que esa continuidad se expresa en la perpetuación y potenciación de espacios denominados "globales" y en las prácticas urbanas de consumo cultural que los caracterizan.
\end{abstract}




\begin{abstract}
As many cities in Latin America, during the 1990s, Buenos Aires City was the scene of various dizzying changes associated, with greater or lesser emphasis, to the imperative of entering on a global stage. Some areas that decades ago were the reason of the metropolis' pride, and where the nineteenth century, through the urban boom, had installed a symbol of the power of the emerging nation-state, began to be abandoned in favor of new or recycled neighborhoods that revealed an aesthetic or cultural mark. In this way, the neoliberalism succeeded in printing its signs in the city: the setting-up of new neighborhoods (Puerto Madero, for example); the recycling of other existing neighborhoods by private actions (Palermo), the emergence of shopping malls situated in converted old and abandoned structures, and so on. After the great argentinian crise in 2001, these processes where integred into an emphasized oppostion that suggested a breakdown between the "neoliberal decade" (the 1990s) and the following decade. This article proposes, on the contrary, that there is a cultural continuity between the 1990s and the 2000s city, and suggests that this continuity is expressed in the perpetuation and empowerment of spaces called "global spaces", as well as it is expressed in some urban practices associated to the cultural consumption.
\end{abstract}

Keywords city, neoliberalism, cultural consumption, Buenos Aires.

\title{
Puesta en situación
}

Uno de los lugares comunes del discurso de y sobre la cultura en Argentina posterior a la debacle de diciembre de 2001 es el que afirma que la conmoción social derivada de la gran crisis decantó en una reinvención de lo comunitario. Las lecturas interpretativas del movimiento político y urbano de los años inmediatamente posteriores a la crisis destacaron la apropiación de la ciudad como espacio colectivo, la reactivación de prácticas ciudadanas en espacios públicos y la emergencia de formas culturales que entretejían elementos locales y rechazaban otros impuestos por un liberalismo "sin freno". A lo largo de la década de los 2000 se fue cristalizando, en las páginas de los suplementos culturales de los diarios de tirada masiva, en los ensayos que reflejaban el pensamiento sobre la política, en los debates, en las mesas redondas, en ocasión de presentaciones de libros y revistas, en los múltiples espacios de constitución de una cultura que provisoriamente denominamos letrada, siguiendo a Ángel Rama 
CATEDRAL TOMADA: Revista de crítica literaria latinoamericana / Journal of Latin American Literary Criticism Ciudad global y consumos culturales en la ciudad de Buenos Aires de fin de siglo XX: continuidades y rupturas del neoliberalismo.

(1985), una oposición palpable entre la década neoliberal de los noventa y la década siguiente. Los años dos mil quedarían de allí en más asociados al renacer del Estado con las sucesivas presidencias de Néstor Kirchner (2003-2007) y su esposa Cristina Fernández (2007-2011 y 2011-2015). Sin embargo, esta oposición, evaluada desde las prácticas culturales urbanas, no resulta tan nítida. La hipótesis de este artículo es que, por el contrario, existe una continuidad entre las prácticas de consumo cultural de los noventa y los años dos mil, y que esa continuidad se expresa, precisamente, en las formas urbanas. ¿Por qué vincularlas con las prácticas de consumo cultural? Como señala Néstor García Canclini (2006), la aplicación del término consumo a la cultura suscita paradojas. Por un lado, las derivadas de referirse a "bienes espirituales" cuya apropiación parece vincularse con lo suntuario; por el otro, las que decantan de considerar que el consumo se planifica y dirige. Sin embargo, las paradojas obligan precisamente a una nueva conceptualización: García Canclini entiende el consumo cultural como “el conjunto de procesos de apropiación y uso de productos en los que el valor simbólico prevalece sobre los valores de uso y de cambio, o donde al menos estos últimos se configuran subordinados a la dimensión simbólica" (89). El consumo cultural alude entonces a aquella apropiación y disfrute de bienes culturales a gran escala y que por ello, para García Canclini, se produce principalmente dentro del espacio urbano. En síntesis, es un consumo que, no por ser masivo, es uniforme y planificado, un fenómeno de interacción en una trama compleja de comunicación marcado, en la gran urbe, por cierto anominato.

Plantear cuál era la situación de Buenos Aires en la década de 2000 supone una mención a la crisis de diciembre de 2001 que ofició de bisagra en múltiples aspectos concernientes a la ciudad. Los días drásticos del verano 20012002 deben ser considerados en toda su excepcionalidad, ya que el modo en que el clima popular fraguó en el espacio público no tuvo parangón con ningún hecho político y social de los años precedentes. El movimiento popular, principalmente urbano, hizo presente en la conciencia colectiva una urgente reflexión por la Nación bajo la forma de grupos que se reunían en las calles. En la ciudad de 
Buenos Aires, muchas de las zonas que décadas atrás habían sido orgullo de la metrópolis -las áreas céntricas, como Avenida de Mayo, las dos peatonales Florida y Lavalle, la mítica "calle" Corrientes-, habían caído en el olvido: esto sucedía porque en los noventa habían surgido nuevos espacios que, al atraer a los paseantes, habían provocado la ruina de aquellos espacios más tradicionales donde el auge constructor del siglo XIX había afincado el poderío de un EstadoNación en crecimiento. Después del 2001, y pese al intento de reactivación con finalidades turísticas, las áreas tradicionalmente céntricas profundizaron la degradación iniciada en los noventa y pasaron a constituirse en el paisaje obligado de la realidad urbana invisibilizada hasta entonces: espacios febriles de día, pero territorios desolados luego del ocaso, o habitados por los cartoneros, individuos que con un carro de fabricación propia y tracción a sangre recogían los residuos reciclables que dejaba al terminar el día la zona de oficinas.

Sin embargo, a fines de 2001 los signos que el neoliberalismo había dispersado en la ciudad no eran motivo de preocupación. El Estado había impulsado, en la década de 1990, la formación de nuevos barrios en antiguas zonas portuarias o industriales (Puerto Madero); se habían reciclado otras con una activa vida previa y en manos de emprendimientos particulares (Palermo); habían surgido shoppings urbanos basados en la idea de reconversión de antiguas estructuras abandonadas (el antiguo mercado del Abasto, pero antes el antiguo mercado Spinetto, el Patio Bullrich, y otros tantos extramuros). En el momento inmediatamente posterior a la crisis, había otras urgencias, y se especulaba con que estas "novedades urbanas" iban naufragar en la misma incertidumbre en la que había naufragado el Estado, junto con los dólares de los ahorristas y la ingenua pretensión de haber vivido, durante los años neoliberales, dentro de unos falaces sueños primermundistas. De allí que los hechos del 2001 se presentaran como una suerte de "despertar" que iba a disolver las vagas fantasmagorías de haber pertenecido al primer mundo global, y que por ello podían reconstituir una política en la polis como opuesta a una política de la globalización (al menos hasta tanto el Estado se recompusiese, aun si pocos lo creían posible). Así se 
CATEDRAL TOMADA: Revista de crítica literaria latinoamericana / Journal of Latin American Literary Criticism Ciudad global y consumos culturales en la ciudad de Buenos Aires de fin de siglo XX: continuidades y rupturas del neoliberalismo.

puede comprender que uno de los primeros efectos de la crisis en Argentina haya sido un cierto "retorno a lo nacional" en el entusiasmo del renacer comunitario y con las aguas políticas aún agitadas. Este retorno a lo nacional expresaba el descontento global por el gobierno de Carlos Saúl Menem (1989-1995 y 19951999) y sus secuelas.

En término de tendencias urbanas, y considerando a Buenos Aires, la ciudad capital, la "vuelta a lo nacional" posó su atención en el viejo barrio colonial de San Telmo, en el tango como forma cultural y en los tropos de una Argentina for export. Pero cuando esto sucedió, se produjo una constatación inevitable: el tejido de la urbe parecía irreversiblemente transformado por la década neoliberal, y más allá de las políticas culturales destinadas a un turismo reanimado por la devaluación del dólar, las antiguas zonas céntricas habían radicalizado un estado de abandono. Si en los noventa habían sido relegadas por no ser moldeables a un supuesto aggiornamento nacional, o por no ser tan sencillamente adaptables al (re-)ingreso de Argentina a un supuesto "Primer Mundo", ahora (después de los dos mil), se atribuía su decadencia a la profunda crisis del Estado, aunque más fundamentalmente a una cierta e inasible "torsión" del gusto del público hacia otra clase de consumo - principalmente en el tiempo de ocio- que el que podían ofrecer esas antiguas zonas céntricas, alicaídas y despobladas.

En efecto, lo que había sucedido en los noventa, y no parecía incluido en ninguna reflexión sobre lo comunitario, era una torsión de las prácticas culturales sin antecedentes, una torsión que tuvo mucho que ver con ciertas pretensiones de globalidad anhelada por las mismas capas medias que asignaban al Estado lo insidioso de sus males y su propia trabazón en una escala de anhelos colectivos. Nuestra hipótesis es que este nuevo tipo de formación del gusto tuvo su forja en la ciudad, y que su permanencia excede la coyuntura de los noventa para llegar al presente. No sólo eso: consideramos que los modos de recorrer y habitar la ciudad en los noventa son clave para entender la ciudad de los dos mil. Corresponden a la acción específica de un grupo letrado y a una acción concreta de promoción de 
ciertas formas de la cultura sobre otras; se vinculan con una pulsión de acoplamiento a movimientos globales que tuvo una expresión concreta en la ciudad.

Señala el arquitecto Adrián Gorelik que el trazado de la ciudad es terreno de disputa y que el espacio es mucho más que un escenario; el espacio público es para él una suerte de coyuntura "en la doble acepción de coyuntura: como ocasión puntual en la historia y como contacto de esferas diferentes" (La grilla y el parque 20): el espacio público es la manifestación privilegiada del contacto entre esferas diversas y el lugar donde se dirimen las variables de la identidad social. De allí nuestra voluntad de leer la arquitectura como espacio de definición y expresión de los sueños colectivos, pues expresa con enorme claridad el sustrato ideológico que guía la vida de la comunidad.

\section{El entretejido imaginario de la urbe}

La década de 1990 demostró que, una vez más, la ciudad podía reinventarse al compás de una demanda de cambio. Distintos tipos de signos se imprimieron en el plano urbano como signos del capitalismo global al mismo tiempo que signos de la cultura: estos signos no fueron únicamente los logotipos o símbolos de las marcas omnipresentes en el comercio de todo mundo. Los signos globales impresos en la superficie de la urbe incluyeron la práctica del reciclado o la reconversión de la urbe en materia significante mercantil. Es suficiente volver a las dos verdaderas "revoluciones urbanas" de los noventa en Buenos Aires, los barrios porteños de Palermo y Puerto Madero, para constatar que, luego del 2001, ambos barrios no dejaron de crecer. Lejos de haber sido algún efecto transitorio derivado del "hechizo neoliberal" de las políticas del presidente Carlos Menem, ese circuito de consumo desmedido que todavía hoy constituye la obscenidad más clara de Buenos Aires, siguió gozando de buena salud. No fueron abandonados en 
CATEDRAL TOMADA: Revista de crítica literaria latinoamericana / Journal of Latin American Literary Criticism Ciudad global y consumos culturales en la ciudad de Buenos Aires de fin de siglo XX: continuidades y rupturas del neoliberalismo.

sus dinámicas como un sueño trunco de la historia; por el contrario, esos nuevos barrios urbanos, trendy (colocando el énfasis en una cultura del espectáculo), crecieron mientras se afianzaban, para las clases medias urbanas, como paliativo contra un "afuera urbano" cada vez más estremecedor. De allí que sea lícito pensar en Palermo y Puerto Madero como algo más que barrios reciclados o remodelados: son síntomas y prueba de una continuidad sin fisuras en términos de consumo cultural desde la década neoliberal hasta el presente.

El marco en el que se gestaron los cambios urbanos de la década de los noventa partía de la hipótesis fuerte de un atraso constitutivo del Estado iniciado con la dictadura (1976-1983) y su política de endeudamiento externo. Este atraso se juzgaba culpable de la frustración de "edades de oro" muy dispares: la de una Argentina candidata a Primer Mundo que habría quebrado su destino entre 1880 y 1940; la Argentina de Perón, a la vanguardia de la legislación social; la de los sesenta, en una primera línea en cultura, arte y experimentación (desde el Instituto Di Tella al rutilante prestigio internacional de la Universidad de Buenos Aires). Las modificaciones urbanas llevadas adelante por la última dictadura militar (expropiaciones y trazados de autopistas, entre otras) no alcanzaron para afirmar la idea de una modernización tecnológica; muy por el contrario, la asociación entre "lo público" y el atraso se enfatizó cada vez más y la idea de un Estado elefantiásico e ineficiente estaba a la orden del día ${ }^{1}$. La democracia alfonsinista (1983-1989) puso su empeño en reconstruir una trama comunitaria destrozada. Tras los embates de la dictadura, y su política de demolición de barrios enteros para hacer lugar a una autopista, era lógico, como señalan Adrián Gorelik y Graciela Silvestri (1990), que la democracia asumiera como deuda social la preservación del patrimonio. Sin embargo, observa Gorelik (y no es un hecho menor para pensar la ciudad desde la democracia) estas nuevas miradas estuvieron marcadas por un fuerte antiestatalismo producto de aquella planificación marcadamente estatal. : mientras la ciudad se “demolía”, las líneas

${ }^{1}$ La ligazón entre las obras del intendente de Buenos Aires Osvaldo Cacciatore (1976-1982) y la deuda externa eran por entonces ya elocuentes. 
teóricas endurecían la crítica frente a la planificación centralizada y apostaban por formas comunitarias de revivir la ciudad. De allí uno de los interrogantes clave para una historia urbana local: por qué, una década después del advenimiento de la democracia, ese antiestatalismo produciría, paradójicamente, "una acepción mercadocrática de la producción de la ciudad” (Gorelik, Miradas 27) relacionada con la decadencia de los espacios públicos. Esta "aceptación mercadocrática" se produjo en sincronía con la entrada de capitales asociada al neoliberalismo, en un movimiento sin resistencias que acompañó modas culturales llegadas de afuera. Así fue como durante los noventa se pensó que estar a la altura de las denominadas ciudades del "primer mundo", ser globales, implicaba no sólo el intercambio de cierto tipo de mercancías, sino que también suponía la renovación del parque tecnológico y el remozamiento de los espacios de una ciudad capital que tenía que ser explotada, como señalamos, en términos de historia. Desde ya que esos espacios, explotados desde este lugar, colaboraban, como dijimos, en la ruina de otros espacios más tradicionales donde se había afincado el poderío de un Estado-Nación en crecimiento.

\section{Otras figuras en el plano}

El movimiento fue gradual y sincrónico, y una ola de reciclaje fue descubriendo el pasado de la ciudad al mismo tiempo que recubría las asperezas de décadas de abandono. Hay un hecho incontestable que pudo haber sido el puntapié de algunos de los cambios más notables y forjar el linaje de una ciudad espectacular: Buenos Aires, a principios de los noventa, carecía de aquello que en ciudades como Nueva York, incluso París, eran los barrios de consumo cultural, aquellas zonas que a partir de la década de 1970 remitían a la idea de "barrio diseñado por las clases acomodadas para ser redimido por el arte; lugar donde un cuadro expuesto en determinada galería y con adecuada inauguración de muestra triplica su valor sin más; territorio donde lo mostrado se une con el receptor para 
CATEDRAL TOMADA: Revista de crítica literaria latinoamericana / Journal of Latin American Literary Criticism Ciudad global y consumos culturales en la ciudad de Buenos Aires de fin de siglo XX: continuidades y rupturas del neoliberalismo.

dar forma a la exhibición definitiva” (Rombouts 2). Si el arte era visto como el motor de estos barrios, era porque se precisaba un movimiento de artistas que recuperara de modo organizado "viejos" espacios de la ciudad, como sucedía en Nueva York o tímidamente ya en Berlín. Y tenía que confesarse por parte de las capas medias de la ciudad alguna voracidad por el consumo de cultura. Ricardo Manetti lo expresaba en términos elocuentes en aquella misma nota periodística: "[El fenómeno] tiene que ver con la necesidad de consumir cultura. Es la misma necesidad que tienen de consumir televisores. Existe una ansiedad de consumo ilimitada. Una necesidad de mostrar un yo en acto de consumir" (Rombouts 3).

Asombra constatar, si se leen los diarios argentinos de principios de los noventa, que nadie creyera posible que algo así sucediera en Buenos Aires. Sin embargo, apenas tres o cuatro años el proceso de constitución de un barrio de esta índole comenzó a manifestarse de la mano de la lenta metamorfosis del viejo barrio porteño de Palermo, a partir de la instalación de locales de artesanías y talleres de artistas. Este movimiento no procedió mediante la demolición y reconstrucción del espacio sino mediante la remodelación y reciclaje, particularmente de las antiguas casas de principios de siglo. El primer polo del futuro y expandidísimo Palermo Hollywood (denominado así porque pronto se instalaron en él productoras televisivas y comenzó a ser transitado cotidianamente por gente famosa y estrellas de TV) combinó entonces cafés-librerías (una novedad en sí a tono con una mutación de la cultura) con algunos locales de indumentaria de índole exclusiva, aunque escasos, y otros tantos bares de cariz nocturno. El tipo de producto exhibido invitó a un público de clase media con aspiraciones estéticas y alguna disposición a consumir. La fluidez de la mercancía cultural, como señala Guy Debord tuvo mucho que ver con el origen de esa pulsión de cambio de esta vasta zona urbana. Palermo fue el primer síntoma que, en los noventa, quebró el horizonte previsible de una ciudad que parecía incapaz de resurgir del molde estatuido por generaciones anteriores de planificadores y urbanistas, y que tiene significación para nosotros como índice de un cambio epocal. 
El segundo síntoma a considerar fue Puerto Madero, que se comienza a reciclar y reformar más visible y formalmente en la década de 1990. En 1989, los ministerios de Obras y Servicios Públicos y del Interior, junto con la Municipalidad de Buenos Aires, crean la Corporación Antiguo Puerto Madero Sociedad Anónima, y el Estado transfiere 170 hectáreas del antiguo puerto para un nuevo tipo de urbanización. Luego de un concurso estatal abierto, surge el plan de urbanización que contemplaba el reciclaje de los docks y -en una segunda etapala construcción de edificios para vivienda. Paralelamente al reciclaje de los docks, se inicia la construcción de edificios con finalidades comerciales, dentro de los cuales el primero en concluirse será el edificio de la compañía Telecom hacia fines de la década. Para entonces ya gran parte de los docks había sido reciclada (entre 1991 y 1996) y funcionaban en ellos oficinas, así como un naciente sector gastronómico que sería uno de los ejes de mayor desarrollo de Puerto Madero. Todavía hoy, y excluyendo a los paseantes de fin de semana, la vida cotidiana del barrio está íntimamente vinculada con las empresas que tienen allí sus sedes; se han instalado algunos locales de tecnología de última generación (elementos informáticos, electrónicos vinculados al ocio, y vehículos de alta gama) y "espacios" indefinibles, como el Hotel Faena, básicamente dedicado a las artes. E1 sistema de docks-restaurants-oficinas y las torres de vivienda producen un tipo de espacio público asimilable al que Fredric Jameson describía para el Hotel Bonaventura (1991): aislamiento y corte respecto de la ciudad, espacios autorreferenciales, visión del resto de la ciudad como espectáculo, refracción del paseante respecto de los edificios, uso predominante del cristal espejado, controles y presencia de seguridad que intimidan o disuaden al paseante ocasional.

Sin soslayar las diferencias entre ambos barrios (en la escala edilicia, en el estilo de paseo al que invitan, en la clase de bienes culturales que promueven, en el habitante prototípico que sugieren), estamos en condiciones de afirmar que ambos responden a un mismo formato de movimiento del capital. Palermo y Puerto Madero, las dos revoluciones urbanas propias de la ciudad de Buenos 
CATEDRAL TOMADA: Revista de crítica literaria latinoamericana / Journal of Latin American Literary Criticism Ciudad global y consumos culturales en la ciudad de Buenos Aires de fin de siglo XX: continuidades y rupturas del neoliberalismo.

Aires en los noventa, deben ser considerados como dos caras de la misma moneda. Pese a sus aparentes diferencias, ambos funcionaron como sendas invitaciones a un modelo de consumo particular habilitado por la convertibilidad y el intercambio de bienes culturales permitido por la paridad cambiaria. Ambos, Palermo y Puerto Madero, se opusieron al shopping, no tanto por el tipo de bienes ofrecido sino por el modelo de consumidor sugerido, refractario a la masa. Los hermana la construcción de una Buenos Aires espectacularizada que recurre a referentes similares: Puerto Madero cultiva el centro, el tango, los vinos, la carne, la cercanía con San Telmo, el río; Palermo a Borges, la temporalidad demorada de otros tiempos, las casas bajas, algún pasado de malevos (así como el shopping recurrirá a la idea de viejo mercado, Spinetto primero, Abasto y otros mencionados); y esa Buenos Aires espectacularizada requiere una sutil fusión de los espacios "viejos" con sus aditamentos nuevos, así como la aparición de una arquitectura que podemos denominar, con Jameson, posmoderna, basada "en el mecenazgo por parte de los negocios multinacionales, cuya expansión y cuyo desarrollo son estrictamente contemporáneos con esta arquitectura” (Jameson 20). En síntesis, ambos barrios fueron índices de que los tópicos del paseo cultural por el centro tradicional habían caducado.

La consideración de lo "nacional" hace necesaria una observación adicional: en los discursos sobre la globalización, "lo global" se suele oponer al Estado-Nación. Las referencias a los noventa no evitan este lugar común: se da por sentado que la entrada de capitales fue en detrimento del Estado. Ahora bien, como señala Saskia Sassen, no hay posibilidad de inserción en lo global que no cuente con la cooperación estatal. Global y local, señala Sassen, lejos de ser dominios discretos, secciones espaciales recortadas, son instancias solapadas y de interpenetración continua: "uno de los modos de conceptualizar estas inserciones de lo global en la producción de lo nacional es bajo la forma de una parcial e incipiente desnacionalización de aquello que, históricamente, había sido construido como lo nacional, o más bien de ciertas propiedades de lo nacional." (Spatialities and temporalities 265). Evaluar el rol del Estado, además de seguir el 
eje de la pulsión cultural, es otra manera de abordar la continuidad postulada. Pues el Estado no sólo constituyó, en el caso argentino, la Corporación Antiguo Puerto Madero; asumió también las inversiones en infraestructura para un nuevo barrio cuyo destino todavía parecía una aventura de incierto resultado. Mientras algunas empresas adquirían docks y planeaban su reciclaje, no se comprometían en la inversión necesaria para convertir el área en barrio (tendido de infrastructura, agua, cloacas, electricidad, telefonía entre otros). Fue el Estado el que realizó la inversión a su propio riesgo y pérdida: si el experimento urbano "resultaba", las empresas pagarían su parte a futuro; si fracasaba, la aventura les habría costado cero. Entonces la supuesta globalidad del antiguo barrio del puerto, Puerto Madero, no fue algo impuesto a un Estado pasivo que no supo "impedir" la entrada de la inversión: ese Estado la sostuvo y propició. Eso vuelve menos paradójico el hecho de que, una década después, el barrio fuera el elegido por cierto sector de la clase política de gobiernos de muy distinto signo, como fue el caso del funcionariado de los gobiernos sucesivos del matrimonio Kirchner: el Estado no fue ajeno a estos movimientos en un sentido general, aunque las lecturas retrospectivas posteriores a los 2000 sugieran lo contrario.

Es de destacar que los dos barrios centrales en la revolución urbana de los noventa fueron refractarios a la idea de ruina real al mismo tiempo que espectacularizaron el pasado por y desde ruinas. En eso también, en la conversión de la ruina en trama significante, Palermo y Puerto Madero pueden ser leídos como enormes síntesis del devenir de la cultura urbana e intelectual de Buenos Aires; experiencias urbanas de distinto calibre que nos permite sopesar la continuidad de ese mundo de sueños y esperanzas que también fueron los noventa.

\section{El espacio de la cultura}


CATEDRAL TOMADA: Revista de crítica literaria latinoamericana / Journal of Latin American Literary Criticism Ciudad global y consumos culturales en la ciudad de Buenos Aires de fin de siglo XX: continuidades y rupturas del neoliberalismo.

Cuando se aborda la constitución de las élites a fines del siglo XIX y el cambio de Buenos Aires de "gran aldea" a capital de Estado, se subraya la intención de aquellas élites gobernantes de imprimir en la ciudad los signos de una vida "civilizada" tal como el concepto se delineaba por entonces. La integración de la naciente República a un mercado internacional de materias primas hacía necesaria la homologación y la puesta a tono en el plano de la cultura. A fines del siglo XX, iguales objetivos quedaron en manos de otro tipo de élite: se trataba ahora de una élite inversora que concebía al espacio urbano en términos de explotación económica y que concebía a la historia en términos de capital cultural. Aunque no hubo claramente una élite letrada que apoyara explícitamente estos proyectos de cambio desde el espacio funcionarial, sí hubo una élite cultural y letrada que fue convocada y respondió a modo de consumidora para la forja de nuevos recorridos. En este sentido es que podemos considerar a la década de 1990 como un momento altamente significativo en el que se produce un giro en la apariencia de ciertas partes de la ciudad articuladas con modificaciones sucedidas en otras. Ciertos discursos de la cultura, al menos los cristalizados en los medios de comunicación, más particularmente en los suplementos culturales, de los que extraeremos algunos ejemplos, apoyaron, propiciaron y clamaron por esos consumos culturales que estaban indisolublemente vinculados con los cambios en la ciudad. ¿Por qué extraer estos ejemplos de los suplementos culturales? Porque, por su circulación y por su versatilidad permiten seguir procesos que afectan tanto a la ciudad como a la producción y consumo de la mercancía cultural².

${ }^{2}$ El análisis de la década de 1990 a través del consumo cultural tal como se expresa en los suplementos culturales del período fue parte de mi trabajo doctoral (cuya hipótesis se vinculaba con el planteo de mutaciones de la figura del intelectual en relación con los cambios urbanos y los cambios en este tipo de consumo). Los ejemplos que se citarán en este trabajo fueron extraídos del corpus constituido a fin de trabajar aquella hipótesis, un corpus que estaba formado por todos los suplementos culturales de la década de dos diarios argentinos de gran tirada (Clarín y Página/12). En este caso también se han tomado ejemplos de suplementos culturales de la década de 2000. 
La consideración de lo sucedido en la ciudad antes y después del 2001 comenzó a organizarse en pares antitéticos, invisibilizando las conductas de los grupos intelectualizados y letrados en el desarrollo de los espacios urbanos como Palermo en los noventa y postulando que la ciudad de los 2000 era una creación prácticamente ex novo. Algunos ejemplos iluminan estas lecturas. Un ejemplar de la Revista N (suplemento cultural del diario Clarín $^{3}$ ) del año 2006 se entregaba a definir la "cultura fashion", el tema de tapa, como fenómeno urbano reciente y desconcertante. Señalaba la bajada de la nota: "[Cultura fashion es] Una corriente inmaterial, que da sello de exclusividad y vanguardia, como en épocas pasadas lo daba Warhol en Nueva York o el propio Instituto Di Tella en Buenos Aires" (VVAA, Cultura fashion tapa). La nota homónima refería a "estilos, actitudes, personajes, artistas: un puntual itinerario conduce a los lugares de moda". El "hilo inmaterial", el "fashion del momento", delimitaba lo que era vanguardia y exclusivo: "aunque fashion es la palabra de la que todos huyen, define bien esta simbiosis que ocurre en Puerto Madero y en Palermo Soho, en las galerías de punta, los desfiles de diseñadores independientes y tiendas de grandes marcas" (VVAA, Cultura fashion 6).

Cuatro eran los espacios de la cultura fashion, abordados en distintas subnotas: Puerto Madero, Palermo, el MALBA ${ }^{4}$ y el espacio inmaterial "de los famosos". Pero sucedía que no eran novedades pos-2001: los dos primeros encuentran sus orígenes a principio de los noventa; el tercero se inaugura apenas cruzados los dos mil. Lo que es destacable en esta definición del fashion de mediados de los dos mil es que da por sentada esa alianza que se había ido trabando, aparentemente de subito, entre cultura y mercado. En la nota, el fashion no se filiaba en los noventa: no se filiaba en ninguna parte. Las prácticas propias del barrio de Palermo, su apropiación por artistas visuales y de los otros, parecía

${ }^{3}$ La Revista $\tilde{N}$ de Clarín fue el primer suplemento cultural de un diario argentino planteado para ser vendido independientemente del diario. Editó su primer número el 4 de octubre de 2003.

${ }^{4}$ Museo de Arte Latinoamericano de Buenos Aires, emprendimiento privado fundado por el empresario y mecenas Eduardo Constantini en el año 2001 en uno de los barrios más exclusivos de la ciudad. 
CATEDRAL TOMADA: Revista de crítica literaria latinoamericana / Journal of Latin American Literary Criticism Ciudad global y consumos culturales en la ciudad de Buenos Aires de fin de siglo XX: continuidades y rupturas del neoliberalismo.

haberse constituido de un día para el otro. Patricia Kolesnicov, autora de otra nota sobre Palermo de los albores de la década (Kolesnicov 18), comparaba a Palermo de los 2000 con la vanguardia de la calle Florida de los '60, o la Corrientes de los ‘70. Destacaba que en Palermo vivían artistas, músicos, y que el lugar era un semillero de salas teatrales, galerías y exposiciones:

cuando la crisis se hizo pico y cayeron el peso y los viajes a Nueva York, Palermo se sostuvo como refugio de ese gusto aprendido e hizo virtud ahora se exporta diseño- de aquello que decía Jorge Luis Borges, fundador mitológico del barrio: que un argentino es heredero legítimo de toda la cultura occidental. El diseño también está en la ropa, que es como la cocina de los restós- de autor. (Kolesnicov 19)

Muchas son las operaciones ideológicas que sostienen este discurso y que rescatamos por ser emblema del modo en que se leyó la década neoliberal de 1990. La primera de esas operaciones es la que hermana a Palermo con Nueva York como espacio trasnacional de la cultura: el paseo por Palermo, entonces, se plantea como la reedición del viaje al exterior, o su supervivencia entre las cuatro murallas de la ciudad. La segunda es la que consiste en apartar los procesos de mercantilización de la cultura que se despliega en Palermo de cualquier idea de industria. Como señalaba el sociólogo Luis Alberto Quevedo, Palermo puede ser visto como el resultado de las carreras de diseño que se crearon en el país a mediados de los ochenta, un diseño que no opone unicidad al carácter masivo, que no opone moda a cultura (Quevedo 19). Junto con el revival y el tratamiento de lo kitsch, Palermo dio cabida a toda una pasión por lo natural, papeles reciclados, velas aromáticas, jabones, elementos de ambientación ecológicos. Adicionalmente, en el crecimiento continuado de Palermo, en la multiplicación de los espacios de la cultura, se afianzaron rasgos que pueden asimilarse a lo que Jameson detectaba, en la producción intelectual llamada "posmoderna": el 
borramiento de la frontera entre la alta cultura y la cultura de masas, comercial o (aunque no es lo mismo) popular.

El crecimiento de un barrio de esta índole se podría asimilar entonces a una deriva cultural global. Otros medios, como el tradicional diario La Nación, también se ocupaban del fenómeno. Palermo (estamos en el 2008) es "una suerte de capital cultural de Buenos Aires", "hervidero intelectual, sofisticado laberinto consumista" (Meneses 4). La imaginería publicitaria de los negocios de ropa de marca que se instalaban allí aludían directamente a un estilo de consumidor (o consumidora) típico del barrio: un poco vintage, un poco hippie-chic. "Muy lejos del campo y de las vacas, el Palermo de hoy parece funcionar - para escritores, pero también para editores y críticos- como una suerte de ventana abierta por la que observar lo que está sucediendo, ahora mismo, on line, en el resto del mejor mundo" (Meneses 6). Y esto parecía ser lo que siempre se había anhelado para la ciudad (Isola 8) en un sueño iniciado en los noventa y que creció de la mano del diseño (Picabea 7), en un puro espectáculo en el sentido debordiano (2007). No es azaroso que, como menciona otra nota (Pavón 18), precisamente a mediados de los dos mil la UNESCO haya incluido a los itinerarios culturales como una nueva categoría en las Directrices de la Convención del Patrimonio Mundial: el turismo cultural, que sugería y apoyaba la revalorización turística de zonas con clara esencia cultural.

Los bienes culturales, en efecto, son el eslabón perdido que, al plantear una relación privilegiada con ciertos espacios de la ciudad, tienden el puente entre dos décadas y nos permiten sospechar del corte tajante entre el neoliberalismo y después. Se puede afirmar que gran parte de las lecturas posteriores al 2001 invisibilizaron el lazo que sujetaba las operaciones de instalación de la mercancía cultural con la convertibilidad que se denostaba (pero que la hacía posible), y más aún con los sucesos acaecidos posteriormente, sucesos que fueron leídos como crisis de la convertibilidad pero que no supusieron una crisis de la cultura instaurada. Esa grieta repentina abierta en la vida nacional se achacaba sencillamente a la economía, pero nada se decía de fenómenos que habían 
CATEDRAL TOMADA: Revista de crítica literaria latinoamericana / Journal of Latin American Literary Criticism Ciudad global y consumos culturales en la ciudad de Buenos Aires de fin de siglo XX: continuidades y rupturas del neoliberalismo.

colaborado en su gestación y que no se habían querido percibir. La cultura se veía como algo desprendido, separado: "en ese clima, la cultura y el arte fueron convertidas de manera inédita en estandarte y herramienta de lucha, en activismo y arena de combate" (Ballester 8). Después del 2001, "las experiencias de las fábricas autogestionadas y los clubes de trueque, que construyeron espacios autónomos por fuera de las leyes del mercado, tuvieron su correlato en proyectos culturales como los de la editorial Eloísa Cartonera o el Proyecto Venus (...)" (8). No hubo sector de la cultura, continuaba Ballester, que no se hubiera visto “impactado o transformado por la conmoción del 2001” (8).

No se exagera lo suficiente cuando se evalúan los movimientos culturales de los noventa. Lo que hemos evidenciado solamente para el barrio de Palermo tiene correlatos en otros espacios de la urbe: una cuidadosa lectura de los suplementos de cultura de la década ${ }^{5}$ parece evidenciar que no hay ningún movimiento pos-2001 que no haya tenido su génesis en ese período de tiempo. Sin embargo, luego de la crisis, se añadió otro elemento, la conversión de la miseria en mercancía en el movimiento avasallante de la ciudad vuelta espectáculo. "Hagamos cosas con las cosas tocadas por los cartoneros: el aura de la pobreza palpita en un bibelot del basural”, decía irónicamente Sarlo (30), para aludir a la valoración por parte de la cultura local (como reflejo también de la mirada global) de elementos que tenían que ver con la cultura de la miseria ahora en primer plano. Si la economía no podía ofrecer cultura para todos, ni riqueza para todos, sí podía ofrecer simulacros de cultura y simulacros de riqueza, señalaba Enrique Lynch (Lynch 10). El capitalismo "puede ser depredador, explotador, implacable, avasallador de las diferencias, pero sobre todo es significante, y lo habitual es que siempre signifique lo mismo, como el fútbol, el estado de la Bolsa y el pronóstico del tiempo en España” (Lynch 11). En ese sistema desbocado de producción de signos, podía suceder que América Latina fuera un productor de signos inédito, a nivel mundial, en lo que concernía a los

\footnotetext{
${ }^{5}$ Ver nota al pie $n^{\circ} 2$.
} 
propios procesos políticos en curso, y que así pudieran generarse discursos que tematizaban lo que sucedía en la ciudad. Una lucha política podía ser también una lucha por la financiación del posicionamiento de América Latina como tema y discurso, y en esta batalla de los signos era lógico que sintiéramos "nostalgia de la ciudad", como señala Olivier Mongin: "Rem Koolhas, que enseña en todas las escuelas de arquitectos, dice: 'La ciudad se terminó, es el caos'. Estamos en un mundo posurbano. A menudo tenemos nostalgia de la ciudad-Buenos Aires, Borges, etcétera-, la ciudad imaginaria, soñada. Porque la ciudad siempre es lo soñado, el imaginario.” (entrevista a Olivier Mongin, Cavanes 10). Esos procesos, precisamente, estaban teniendo lugar en una ciudad de pronto irreconocible.

\section{Derivas de la ciudad real}

La ciudad siempre hizo sentido con sus piedras, pero si Koolhaas señalaba que se nos hacía presente una nostalgia de la ciudad, ya no era la ciudad perdida sino la ciudad imaginaria, soñada, y desvanecida en el torbellino de los signos igualadores del capital. Procesos como los previamente reseñados explican que, diez años después del fin de los noventa, Gorelik constatara que los tan mentados cambios pos-2001 "se realizaron sin que apareciera ninguna voluntad de imaginar un modelo diferente de ciudad y poner detrás de él todas las energías políticas e institucionales [...] Tal el límite del cambio de discursos" (Buenos 39). Los críticos de los cambios iniciados con el neoliberalismo, sin embargo, suelen revelar un prejuicio consistente en entender a estas áreas reformadas como zonas sin incidencia en la "ciudad real" (Observaciones sobre la sociedad 1999), y es de notar que esta observación también revela una continuidad con los noventa, que en una de sus facetas consideró estos cambios como una suerte de "estructura de utilería". Como demuestra Jameson, ellos son otros tantos modos de aparición de lo real, desde el momento en que revelan lo que sucede en la vida social a niveles profundos tanto como esa miseria tantas veces fotografiada y exportada. La 
CATEDRAL TOMADA: Revista de crítica literaria latinoamericana / Journal of Latin American Literary Criticism Ciudad global y consumos culturales en la ciudad de Buenos Aires de fin de siglo XX: continuidades y rupturas del neoliberalismo.

realidad, comúnmente asociada con el real padecimiento social, pocas veces se lee desde las también reales maneras de goce y disfrute de sociedades duales en su núcleo.

Puerto Madero, un segundo ejemplo emblemático, seguía siendo pujante diez años después, y se constataba que, gracias a la artificiosidad del nuevo "puerto", se había evitado la destrucción de la llamada City (el área céntrica de bancos de la ciudad). "Si no se hubiese abierto Puerto Madero la destrucción de la City hubiera sido mayor", decía el arquitecto Juan Manuel Borthagaray (2012). No sólo eso: la presencia del empresario del arte Alan Faena y su inyección de capitales había logrado establecer allí un gran polo de cultura en el llamado Faena Art Center, por supuesto un viejo edificio reciclado de la zona de depósitos del puerto, al igual que el primer emprendimiento del excéntrico personaje, el Hotel Faena. Precisamente en ocasión de la inauguración del Faena Art Center, una década después de la gran crisis, una nota de Alicia de Arteaga recordaba que "era un viejo sueño de Alan Faena convertir el emblemático edificio de Molinos en un centro de arte contemporáneo que proveyera a Puerto Madero del ancla cultural propia de un art district" (Arteaga 24). La directora de Faena Arts Center, Ximena Caminos, también lo enfatizaba: "Buenos Aires no tiene un lugar donde mostrar las vanguardias con nivel internacional” (Pérez Bergliaffa 51). La nota que en el año 2006 acompañaba la definición del fashion y que se dedicaba a Puerto Madero (Páez 6) señalaba que el conjunto edilicio de Faena era denominado "Porteño Art District" por Faena y su socio, y que -“al igual que las vanguardias"- habían redactado un manifiesto propio. Pero también "manifestaban" "que quieren transformar esta zona de la ciudad como el Guggenheim lo hizo con Bilbao" (Páez 7).

Para el artista plástico Daniel Santoro, la globalidad en la plástica indica la aparición de inmensas instituciones "filantrópicas", enormes museos de cariz internacional, la presencia de fundaciones con fondos millonarios y la aparición de una serie de individuos (curadores, especialistas varios) simbióticos con la circulación de dinero en el arte (Santoro 37). También la presencia de curadores y 
galeristas, y el florecimiento de barrios ad hoc. La prolongación de los muros entre las urbes denominadas "globales" se afinca en el financiamiento privado a la cultura y en la centralidad del museo y las galerías, convertido en otro emblema de la continuidad entre los noventa y los dos mil. La inauguración del MALBA en septiembre del 2001 ("prestigioso y fashionable", Hax 8), luego de haber sido preparado como espacio en las postrimerías de los noventa, acopló con un enorme ciclo en el que la cultura puso al museo en un lugar clave del turismo cultural. Lo señala la crítica argentina Andrea Giunta: "puede resultar paradójico que después del 2001, cuando el país salía de una de las mayores crisis de su historia, se produjese un ciclo intenso de expansión y apertura de nuevos museos" (Giunta 14). Puede resultar paradójico cuando las lecturas retrospectivas de lo sucedido en 2001 dan por sentado, primero, que las únicas formas posibles de actividad cultural son las surgidas de los centros culturales comunitarios, las asambleas o las formas de la micropolítica. Misiones, Salta, Rosario, Bahía Blanca (todas grandes ciudades argentinas con vida cultural propia) estaban entre los lugares que habían rehecho sus museos. Giunta lo subrayaba: "[...] fue ésta la década de los museos, sobre todo de arte contemporáneo. Los museos se sumaban a la reactivación de las ciudades en un proceso típico de la gentrificación que actuaba como una variable adicional en la recuperación económica, política y cultural del país" (Giunta 14). La gentrificación alude a los cambios estructurales de un barrio a fin de poder acoplarse a dinámicas culturales denominadas "globales": como señala Mike Featherstone, la esfera cultural se torsiona en virtud de una suerte de cultura de la globalización, y esto sucede en alianza con ciertas formas de cultura constituyendo los procesos de gentrificación (2000). Lo que Giunta no parece advertir entonces en la nota es que, más que una "variable adicional" en la recuperación del país, la gentrificación había comenzado en los noventa y, simplemente, ya no iba a detenerse.

La pregunta que sostiene la evaluación de la ciudad de los noventa debe apuntar a si la gentrificación es una "variable adicional en la recuperación económica, política y cultural" o si los mecanismos de gentrificación tienen 
CATEDRAL TOMADA: Revista de crítica literaria latinoamericana / Journal of Latin American Literary Criticism Ciudad global y consumos culturales en la ciudad de Buenos Aires de fin de siglo XX: continuidades y rupturas del neoliberalismo.

directa relación con los movimientos económicos, políticos y culturales que desembocan en la crisis. La gentrificación, de hecho, tiene una expresión llana en el plano urbano: es algo que acaece a la ciudad. Desde la implantación de obras de arquitectos famosos para que la ciudad acceda "a la dignidad planetaria y turística" (Augé 6), como el caso del Puente de la Mujer firmado por Santiago Calatrava, hasta la creación de un distrito artístico, o de un barrio cultural, la arquitectura confirmó y expresó, durante los noventa, relaciones de poder tendientes a abrir y conseguir mercados bajo una suerte de "plagio de la ideología de los empresarios” (7). La cultura selló su conversión en espectáculo en alianza con los bienes que permitía ingresar la convertibilidad.

Sostenemos que ese movimiento iniciado en los noventa propuso el exilio de los muros reales para abogar por la continuidad de unos muros supuestamente globales, apoyando la deriva de la ciudad hacia puro espectáculo o usina productora de signos. Así se entiende la posterior conversión de la miseria en objeto mercantil-cultural, pues es la ciudad misma, con sus habitantes, sus prácticas, sus más ínfimos recodos, lo que se convierte en reservorio significante. Tal vez la globalización "remite a una forma de circulación mundial marcada por el protagonismo de las ciudades, más que de las naciones", como señalaba Andra Giunta a propósito de las bienales (Giunta 18). En todo caso, tal vez de lo que se trate es del advenimiento de nuevo tipo de urbanita facetado según nuevos cortes respecto de aquellos que modelaban lo moderno: un ciudadano hedonistaconsumidor que, más allá de su pertenencia de clase, aspira, como no sucedía desde hace un siglo, a una cultura universal, ahora denominada "global". 


\section{Bibliografía}

Aguilar, Gonzalo. "De América Latina a aldea global". Revista N, diario Clarín. 26 agos. 2006: 28-29.

Alemián, Ezequiel. "Generación estallido". Suplemento Cultural, diario Perfil. 27 mayo 2012: 8-10.

Arteaga, Alicia de. "El mundo según Neto". Suplemento ADN, diario La Nación. 30 sept. 2011: 24-25.

Augé, Marc. "El futuro de las ciudades". Revista N, diario Clarín. 28 nov. 2009: 6.

Ballester, Alejandra R. "La revuelta como nacimiento". Revista N, diario Clarín. 17 dic. 2011: 8-9.

Borthagaray, Juan Manuel "Puerto Madero evitó la destrucción de la city" (entrevista sin firma a Juan Manuel Borthagaray). Diario Clarín virtual. 29 nov. 2012. Consultado el 1 julio 2016. Recuperado de: http://www.clarin.com/ciudades/Puerto-Madero-evito-destruccion-

City_0_819518139.html.

Cavanes, Mariana. "La lucha por el territorio" (entrevista a Olivier Mongin). Revista N, diario Clarín. 3 feb. 2007: 10-11.

Debord, Guy. La sociedad del espectáculo. Buenos Aires: La Marca, 2007.

Erlan, Diego. "Poso como un divo pero soy una antiestrella" (entrevista a Dani Umpi). Revista Ñ, diario Clarín. 20 ene. 2007: 2.

Featherstone, Mike. Cultura de consumo y posmodernismo. Buenos Aires: Amorrortu, 2000.

Fernández Díaz, Jorge. "Una ciudad dentro de otra". Suplemento $A D N$, diario $L a$ Nación. 14 jun. 2008: 2. 
CATEDRAL Tomada: Revista de crítica literaria latinoamericana / Journal of Latin American Literary Criticism Ciudad global y consumos culturales en la ciudad de Buenos Aires de fin de siglo XX: continuidades y rupturas del neoliberalismo.

García Canclini, Néstor. "El consumo cultural: una propuesta teórica”. En El consumo cultural en América Latina. Construcción teórica y líneas de investigación, Guillermo Sunkel (coord.). Bogotá: Convenio Andrés Bello, 2006: 72-95.

Giunta, Andrea. "La era del gran escenario". Revista Ñ, diario Clarín. 13 ene. 2007: 18-19.

. “Un nuevo mapa museográfico". Revista Ñ, diario Clarín. 28 sept. 2013:

14.

Gorelik, Adrián, y Silvestri, Graciela. "Paseo de compras: un recorrido por la decadencia urbana de Buenos Aires”. Revista Punto de Vista. Buenos Aires. Año XIII, no 37 (1990): 23-28.

Gorelik, Adrián. "Buenos Aires, de la crisis al boom”. Revista Punto de Vista. Buenos Aires. Año XXIX, nº 84 (2006): 33-39.

. "Miradas sobre Buenos Aires: itinerarios". Revista Punto de Vista. Buenos Aires. Año XIV, nº 41 (1991): 21-28.

. "Observaciones sobre la sociedad civil y el estado en Argentina”. Revista Punto de Vista. Buenos Aires. Año XX, no 63 (1999): 9-16.

. La grilla y el parque. Espacio público y cultura urbana en Buenos Aires, 1887-1936. Bernal: Universidad Nacional de Quilmes, 1998.

Hax, Andrés. "Prestigioso y fashionable". Revista N, diario Clarín. 19 sept. 2006: 8.

Isola, Laura. "Un caleidoscopio de estilos". Suplemento ADN, diario La Nación. 14 jun. 2008: 8-9.

Jameson, Frédric. Ensayos sobre el posmodernismo. Buenos Aires: Imago Mundi, 1991.

Kohan, Martín. "Pequeño infierno de la clase media". Revista N, diario Clarín. 17 dic. 2011: 9 . 
Kolesnicov, Patricia. "Mapa para una nueva bohemia”. Revista N, diario Clarín. 11 oct. 2003: 18-19.

Lerer, Diego. "Películas en tiempo presente". Revista Ñ diario Clarín. 26 ago. 2006: 14-16.

Ludmer, Josefina [compiladora]. Las culturas de fin de siglo en América Latina. Rosario: Beatriz Viterbo, 1994. . Aquí América Latina. Buenos Aires: Eterna Cadencia, 2010.

Lynch, Enrique. "La insoportable levedad de todo". Revista N, diario Clarín. 18 nov. 2006: 10-11.

Manso, Diego. "Masticando el cine pochoclo". Revista N, diario Clarín. 26 ago. 2006: 22-23.

Meneses, Juan Pablo. "Palermo, gran manzana cultural". Suplemento ADN, diario La Nación. 14 jun 2008: 4-7.

Páez, Natalia. "Los que miran, actúan”. Revista Ñ, diario Clarín. 18 sept. 2006: 6.

Pavón, Héctor. "La cultura en la ruta del turismo". Revista N, diario Clarín. 30 sept. 2006: 18 .

Pérez Bergliaffa, Mercedes. "La potencia del arte como juego". Revista Ñ, diario Clarín. 1 oct. 2011: 50-51.

Picabea, María Luján. "El diseño crea cultura”. Revista Ñ, diario Clarín. 19 sept. 2006: 7 .

Pogoriles, Eduardo. "Cómo cambió la venta de libros". Revista N, diario Clarín. 21 abril 2007: 20.

Quevedo, Luis Alberto. "El sentido de la vida se construye en el barrio". Revista N, diario Clarín. 11 oct. 2003: 19.

Rama, Angel. "La ciudad letrada". En Morse, Richard y Jorge Enrique Hardoy (comp.) Cultura urbana latinoamericana. Buenos Aires: Clacso, 1985.

Rombouts, Javier. "Uno, dos, muchos centros". Suplemento Metrópolis, diario Página/12. 31 julio 1992: 2-3. 
CATEDRAL Tomada: Revista de crítica literaria latinoamericana / Journal of Latin American Literary Criticism Ciudad global y consumos culturales en la ciudad de Buenos Aires de fin de siglo XX: continuidades y rupturas del neoliberalismo.

Saimolovich, Daniel. "Retrato del cartonero". Revista N, diario Clarín. 17 dic 2011: 12-13.

Sánchez, Matilde. "El impero de las torres". Revista N, diario Clarín. 28 nov. 2009: 9 .

Santoro, Daniel. "La otra mirada". Suplemento ADN, diario La Nación. 5 ene 2008: 37 .

Sarlo, Beatriz. "La estética de las buenas causas". Revista Punto de Vista. Buenos Aires. Año XXIX, no 85 (2006): 29-34.

Sassen, Saskia. "Spatialities and temporalities of the Global: Elements for a Theorization”. En Arjun Appadurai (ed.). Globalization. Arjun Appadurai, editor. Londres: Duke University Press, 2001, 261-278.

Sassen, Saskia. Territorio, autoridad y derechos. De los ensamblajes medievales a los ensamblajes globales. Buenos Aires: Katz, 2010.

VVAA. "2001-2011. Cultura de la crisis". Revista Ñ diario Clarín. 17 dic. 2011: suplemento completo. . "Cultura fashion”. Revista Ñ, diario Clarín. 18 sept. 2006: 6-10. - "Palermo, la gran manzana cultural" (nota de tapa). Suplemento ADN, diario La Nación. 14 jun 2008: tapa. 